\title{
Caffeine and impulsiveness in rats
}

\author{
STEPHEN R. FLORA and MAX A. DIETZE \\ Fort Hays State University, Hays, Kansas
}

\author{
(William B. Pavlik, Sponsor)
}

\begin{abstract}
Two groups of rats maintained at $85 \%$ free-feeding weight (FFW), water-deprived $23 \mathrm{~h}$ daily, received 1-h access to either water or caffeine solution $(0.5 \mathrm{mg} / \mathrm{ml})$ and then $10-40 \mathrm{~min}$ later were tested for impulsiveness (choice of a small immediate reinforcer over a large delayed reinforcer) in a T maze. When they entered one goalbox, the rats would receive one pellet immediately, which we considered to be the impulsive choice. When they entered the other goalbox, the rats would receive six pellets after a delay of $15 \mathrm{sec}$, which we considered to be the self-control choice. Change scores revealed a statistically significant difference $(p<.01)$ between groups, with the caffeine group making more impulsive choices. However, the absolute increase in impulsiveness was small. These results support research on the effects of caffeine on impulsive human behavior, which suggests that if caffeine does increase impulsiveness, the effect is weak. It is suggested that aversive stimulation may increase impulsiveness.
\end{abstract}

The contention that dietary caffeine increases impulsive behavior in humans, especially children, is widely held in pop psychology. However, there is little empirical evidence to support this contention. Rapoport, Berg, Ismond, Zahn, and Neims (1984) found that when "low consumer" children were placed on a high caffeine diet ( $5 \mathrm{mg} / \mathrm{kg}$ twice daily) their parents described a significant increase in aversive behavior. However, "high consumer" children (reported intake $\geq 500 \mathrm{mg} /$ day) were found to be more impulsive when they received placebos and less impulsive when they were on the caffeine diet. Bear (1987) compared the effects of caffeinated and noncaffeinated beverages in kindergarten children and found "'no consistent relationships" between caffeine and several behaviors. This negative finding included the observation that "no consistent relationship between caffeine intake and teacher ratings of 'hyperactive' behaviors was observed in any subject"' (p. 229).

In pigeons and monkeys, caffeine has been found to increase the rate of responding on fixed interval schedules (Davis, Kensler, \& Dews, 1973; McMillan, 1968; but see McMillan, 1979). This suggests that caffeine may increase impulsive responding.

Because the research with children has only produced small and inconsistent findings on the effect of caffeine on impulsive behavior, and related nonhuman research on caffeine has also produced findings with no clear conclusion with regard to impulsive behavior, the present experiment sought to investigate directly the effects of caffeine on impulsive behavior by using the behavioral paradigm of self-control and impulsiveness, with rats as subjects. In the behavioral paradigm, the operational defi-

Requests for reprints may be sent to Stephen R. Flora, Department of Psychology, Fort Hays State University, Hays, KS 67601-4099. nition of impulsiveness is the choice for a small immediate reinforcer over a larger delayed reinforcer; self-control is defined as the opposite choice (see Logue, 1988, for a review).

\section{METHOD}

\section{Subjects}

Twelve female albino rats, approximately 3 months old at the start of the experiment, were used. The subjects were maintained at $85 \%$ FFW and were fed most of their daily food ration immediately after testing. However, because some studies have found that highly deprived rats show increased impulsiveness (e.g., Eisenberger, Masterson, \& Lowman, 1982), the subjects were fed approximately $4 \mathrm{~g}$ of lab chow 4-6 $\mathrm{h}$ prior to each day's testing.

\section{Apparatus}

The apparatus used was a T-shaped maze. The walls and floor were constructed of painted wood, and the roof was clear Plexiglas. The startbox and each of the goalboxes were $33 \times 10 \times 10 \mathrm{~cm}$, and the choice area was $18 \times 18 \times 10 \mathrm{~cm}$. Plexiglas guillotine doors separated the startbox and each of the goalboxes from the choice area. A bottle cap, $2.5 \mathrm{~cm}$ in diameter, was attached to the floor $2.5 \mathrm{~cm}$ from the end of each goal arm and served as the food cup. Diagonal metal tubes came through each end wall of the goalboxes down to the food cups and were used to manually deliver $45-\mathrm{mg}$ food pellets.

\section{Pretraining \\ Prior to the present experiment, all of the subjects participated in an experiment in which we attempted to examine the effects of context on self-control. At the start of pretraining, the startbox was white, the left goalbox was painted with black-and-white $2.5 \mathrm{~cm}$ wide vertical stripes, and the right goalbox was painted black. On Day 1 of pretraining, each rat was confined to each goalbox for $10 \mathrm{~min}$, with 10 food pellets in each cup. For the next 19 days, the subjects were given four trials per day. All of the rats were put in the startbox for $10 \mathrm{sec}$ before the door to the choice area was raised. Immediately after a rat entered a goal- box, the goalbox door was closed and, regardless of choice, the rat re- mained in the arm for $20 \mathrm{sec}$ before being put back into the startbox to begin the next trial. Rats $1-6$ received one pellet immediately after entering the left box (the impulsive choice) and three pellets $10 \mathrm{sec}$ after entering the right box (the self-control choice). For Rats 7-12, the goal- box used for the impulsive choice was the right box, and for the self-}


control choice, the left box was used, which balanced direction across groups. The order in which the groups, Rats 1-6 and Rats 7-12, were tested alternated daily. Following Day 19 of training, the startbox and choice area were painted with black-and-white vertical stripes to test for the effects of context on self-control.

Painting the startbox and choice area in order for there to be a context similar to that of either the impulsive choice (Rats 1-6) or the selfcontrol choice (Rats 7-12) had no effect on choice. Rats 1-6 produced a mean of 2.4 self-control choices for the 8 days prior to altering the startbox and choice-point context and produced a mean of 2.3 for the 8 days after the context was altered. Rats 7-12 produced means of 2.5 for both the final 8 days before the context was altered and for the 8 days after it was altered. Although painting the startbox and choice point with the context of either the impulsive (Rats 1-6) or self-control choice (Rats 7-12) had no effect on preference, Logue and Mazur (1981) found that a contextual cue (overhead lights) presented during delays to reinforcement and associated with the self-control choice was necessary for producing preference for the delayed reinforcer in pigeons.

Because painting the startbox and choice point had no effect on choice, these trials were viewed as pretraining for the present experiment, which investigated the effects of caffeine on choice.

\section{Procedure}

Following pretraining, the rats were returned to their home cages and given free access to lab chow for 2 days; then they were returned to $85 \%$ FFW. The 3rd day after pretraining, all rats received two forcedchoice trials to the left box and then two forced-choice trials to the right box. During forced-choice trials, only the appropriate box was open. For each rat, the self-control and impulsive-choice boxes were the same as in pretraining. All of the rats again received one pellet immediately after an impulsive choice. However, for a self-control choice, the rats received six pellets after $15 \mathrm{sec}$. The rats were in the startbox for approximately $5 \mathrm{sec}$ before the door to the choice point was opened. The rats remained in the box for $5 \mathrm{sec}$ after receiving the food pellet(s).

Following the day of forced-choice trials, all of the rats received four choice trials per day for 6 days as baseline. Except for the changes noted above, the procedure was identical to pretraining. The day after baseline, all of the rats were put on daily water deprivation for the 23-h period following daily testing and maintenance feeding. All of the rats did receive free access to water for $\mathbf{2 0} \mathrm{min}$ with their daily maintenance feeding, which occurred immediately after testing.

Rats 1-3 and 7-9, the caffeine group, were given free access to a $1-\mathrm{mg} / \mathrm{ml}$ solution of caffeinated water for $1 \mathrm{~h}$ daily. Rats 4-6 and 10-12, the control group, were given free access to water for $1 \mathrm{~h}$ daily. After 10-40 min of access to caffeine solution or water, all of the rats received four choice trials as described above. Time to testing depended on the order in which the groups (1-6 or 7-12) were being tested for the day. The experimental phase lasted 4 days.

\section{RESULTS}

During the final 4 days of baseline, both the caffeine and control groups produced means of 9.3 self-control choices over the 16 choice trials. During treatment, the caffeine group produced a mean of 7.8 self-control choices, whereas the control group produced a mean of 10.3. Neither the change in means from baseline to treatment for either group nor the difference between groups during treatment was statistically significant.

Although the raw data produced no significant differences, Figure 1 indicates that there was separation between the groups during treatment. Furthermore, when change scores, defined as the number of self-control choices during the last 4 days of baseline minus the number of self-control choices during the 4 days of treatment, are evaluated, a significant difference between groups is seen. The caffeine group (Rats 1-3 and 7-9) produced change scores of $-1,-3,1,-2,-3$, and -1 , and the

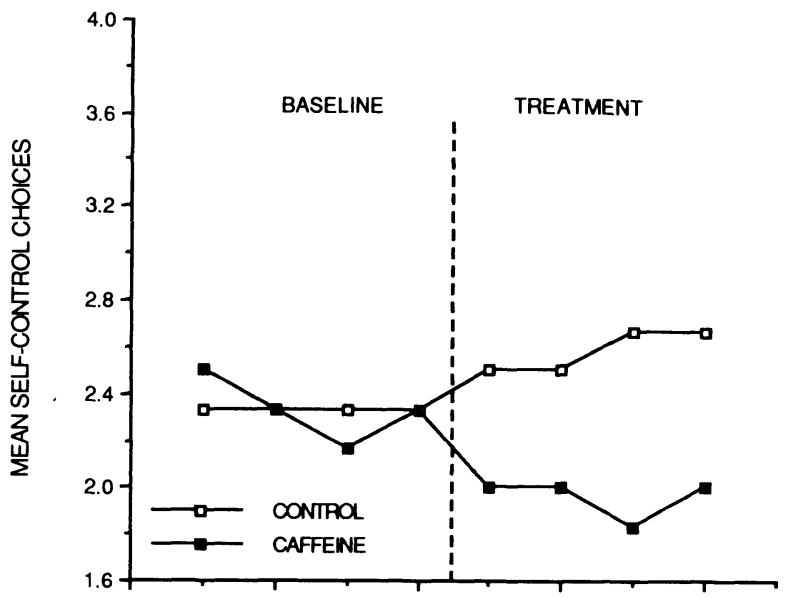

\section{BLOCKS OF FOUR TRIALS PER DAY}

Figure 1. Mean self-control choices per day for the caffeine group and for the control group during the final 4 days of baseline treatment.

control group (Rats 4-6 and 10-12) produced change scores of $2,0,0,1,1$, and $2[t(10)=3.3, p<.01]$. During the 1-h access to either caffeine solution or water, the rats in the caffeine group drank a mean of $8.0 \mathrm{ml}$ of solution, and the control rats drank a mean of $8.9 \mathrm{ml}$ of water (nonsignificant).

\section{DISCUSSION}

The present results show that dietary caffeine may increase the number of impulsive choices made by rats, but, as in children (Bear, 1987), the effect is small and may be due to the small amount of caffeine consumed. To the extent, however, that caffeine does increase impulsiveness, the effect may be attributed to at least two possible reasons. First, as a central nervous system stimulant, small doses of caffeine should lead to increased activity and thus, presumably, increased impulsiveness. This may be the reasoning behind the contention found in pop psychology that dietary caffeine causes impulsive behavior in children.

However, second, Rapoport et al. (1984) found that when "high consumer" children were given a placebo instead of caffeine, they became more impulsive, but when "low consumer" children were given caffeine, they showed increased "aversive behaviors." This suggests that increased impulsiveness may be due, at least in part, to the possible aversive internal state produced by caffeine consumption by caffeine-naive rats (present results) or by low-consumer children, and by the lack of caffeine consumption by high-consumer children (Rapoport et al., 1984). That is, aversive stimulation may increase impulsiveness. In support of this hypothesis, several studies (e.g., Eisenberger et al., 1982; Snyderman, 1983) have found that high degrees of food deprivation (presumably an aversive state) leads to increased impulsiveness (but see Hastjarjo \& Silberberg, 1992). Flora, Schieferecke, and Bremenkamp (1992) found that exposure to aversive noise decreased self-control for positive reinforcement in humans. Taken together, these results suggest a tentative generalization that exposure to aversive stimulation (internal or external) may increase impulsive behavior (even if the impulsive behavior does not reduce or eliminate the aversive stimulation; see Flora et al., 1992).

\section{REFERENCES}

BEAR, R. A. (1987). Effects of caffeine on classroom behavior, sustained attention, and a memory task in preschool children. Journal of Applied Behavior Analysis, 20, 225-234. 
Davis, T. R. A., Kensler, C. J., \& Dews, P. B. (1973). Comparison of behavioral effects of nicotine, $d$-amphetamine, caffeine, and dimethylheptyl tetrahydrocannabinol in squirrel monkeys. Psychopharmacologia, 32, 51-65.

Eisenberger, R., Masterson, F. A., \& Lowman, K. (1982). Effects of previous delay of reward, generalized effort, and deprivation on impulsiveness. Learning \& Motivation, 13, 378-389.

Flora, S. R., SCHIEFerecke, T. R., \& Bremenkamp, H. G. (1992). Effects of aversive noise on human self-control for positive reinforcement. Psychological Record, 42, 505-517.

Hastjarjo, T., \& Silberberg, A. (1992). Effects of reinforcer delays on choice as a function of income level. Journal of the Experimental Analysis of Behavior, 57, 119-125.

LOGUE, A. W. (1988). Research on self-control: An integrating framework. Behavioral \& Brain Sciences, 11, 665-709.

Logue, A. W., \& MAZUR, J. E. (1981). Maintenance of self-control acquired through a fading procedure: Follow-up on Mazur and Logue (1978). Behavior Analysis Letters, 1, 131-137.

MCMilLAN, D. E. (1968). Some interactions between sympathomimetic amines and amine-depleting agents on the schedule-controlled behavior of the pigeon and the squirrel monkey. Journal of Pharmacology \& Experimental Therapeutics, 163, 172-187.

McMillan, D. E. (1979). Effects of $d$-amphetamine and caffeine on schedule-controlled and schedule-induced responding. Journal of the Experimental Analysis of Behavior, 32, 445-456.

RAPOPORT, J. L., Berg, C. J., IsMOND, D. R., ZAHN, T. P., \& Neims, A. (1984). Behavior effects of caffeine in children. Archives of General Psychiatry, 41, 1073-1079.

Snyderman, M. (1983). Optimal prey selection: The effects of food deprivation. Behavior Analysis Letters, 3, 359-369.

(Manuscript received August 10, 1992.) 